\section{Ethnicity and spontaneous clearance of hepatitis $C$ in HIV-HCV coinfected patients}

To the Editor:

There are limited reports suggesting that ethnic populations differ in their immunological response to infection with hepatitis $\mathrm{C}$ virus (HCV), and that host factors influence spontaneous clearance (1). Canadian data (2-5) suggest that Inuit and First Nations people appear to have a higher rate of spontaneous HCV clearance based on the presence of HCV antibody and the absence of HCV RNA. An epidemiological review (6) has demonstrated a high prevalence of $\mathrm{HCV}$ coinfection in HIV-infected populations; we wondered whether there may be evidence of a differential rate of spontaneous HCV clearance depending on ethnicity and, specifically, Aboriginal origins in this coinfected population.

After obtaining ethics approval through the Health Research Ethics Board of the Faculty of Medicine and Dentistry at the University of Alberta (Edmonton, Alberta), the Northern Alberta HIV Program database was examined to identify all living HIV-infected patients found to be HCV-seropositive between January 2001 and December 2006. In the HIV database, 120 charts of 181 individuals meeting our study entry criteria were accessible and reviewed by one of the two authors.

Of the 120 patients reviewed, 74 were men (mean age 43 years; range 23 to 67 years of age). Of HIV-HCV coinfected patients, $52.5 \%$ had self-identified as Aboriginal. Of the 120 reviewed charts, 84 contained results of HCV RNA testing, with $46 \%$ of these patients being Aboriginal compared with $31 \%$ of the total HIV clinic population self-identified as Aboriginal. Assuming that HCV RNA-negative test results reflected spontaneous clearance in the face of HCV seropositivity, 13 of $84(15 \%)$ patients appeared to have had spontaneous clearance of HCV. Of these 13, seven were of Aboriginal origin. This difference was not statistically significant $(\mathrm{P}=0.17 ; \mathrm{OR}=0.7 ; 95 \%$ CI 0.128 to 8.2$)$.

Of the 84 available HCV RNA test results, 71 were positive and interpreted as indicative of ongoing HCV replication. Thirty-two of these positive test results were in self-identified Aboriginal patients, and 39 in nonAboriginal patients. Of these 71 patients potentially eligible for antiviral therapy, only 10 received antiviral therapy for HCV and only two had a clinical response. Both of these were non-Aboriginal patients, and had genotypes $3 \mathrm{~A}$ and $1 \mathrm{~B}$. The single Aboriginal patient who received anti-HCV therapy had genotype $1 \mathrm{~A}$, and did not respond.

Spontaneous HCV viral clearance in populations not known to be HIV-infected has ranged from $15 \%$ to $45 \%$, with significantly lower rates in those who are HIV-HCV coinfected (7). Because of literature (2-5) suggesting population differences in rates of spontaneous clearance and specifically in the Canadian Aboriginal and Inuit populations, we thought it would be of interest to examine this in Northern Alberta's HIV population. Unfortunately, the study was retrospective, relatively small in patient number and incomplete in terms of ascertainment of outcome. Nonetheless, we believed the results were of interest. The relatively low uptake of anti-HCV therapy in this population has suggested the potential merits of a systematic, proactive approach in our population. Studies addressing genetic factors suggest a role for immunological host factors being important in HCV clearance, but these differences may be overshadowed by significant immune deficits as seen in patients with HIV infection.

ACKNOWLEDGEMENTS: The authors thank the staff of the Northern Alberta HIV Program for their assistance in identifying patients.

\section{Lil Miedzinski MD FRCPC Geoff Taylor MD FRCPC University of Alberta, Edmonton, Alberta}

\section{REFERENCES}

1. Aborsangaya KB, Dembinski I, Khatkar S, Alphonse MP, Nickerson P, Rempel JD. Impact of aboriginal ethnicity on HCV core-induced IL-10 synthesis: Interaction with IL-10 gene polymorphisms. Hepatology 2007;45:623-30.

2. Minuk GY, Uhanova J. Viral hepatitis in the Canadian Inuit and First Nations populations. Can J Gastroenterol 2003;17:707-12.

3. Minuk GY, Zhang M, Wong SG, et al. Viral hepatitis in a Canadian First Nations community. Can J Gastroenterol 2003;17:593-6.

4. Grebely J, Conway B, Raffa J, et al. Natural history of hepatitis C virus infection among injection drug users in Vancouver, Canada. Hepatology 2006;42:230A. (Abst)

5. Hill WD, Butt G, Melanson P, et al. Spontaneous clearance of Hepatitis $C$ virus among aboriginals in British Columbia. Can J Infect Dis Med Microbiol 2006;17:67-8. (Abst)

6. Alter MJ. Epidemiology of viral hepatitis and HIV co-infection. J Hepatol 2006;44:S6-9.

7. Piasecki BA, Lewis JD, Reddy KR, et al. Influence of alcohol use, race, and viral coinfections on spontaneous HCV clearance in a US veteran population. Hepatology 2004;40:892-9. 


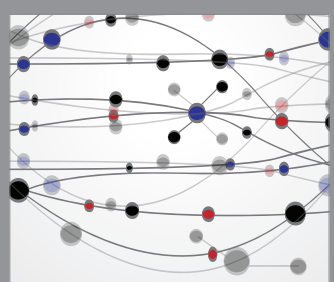

The Scientific World Journal
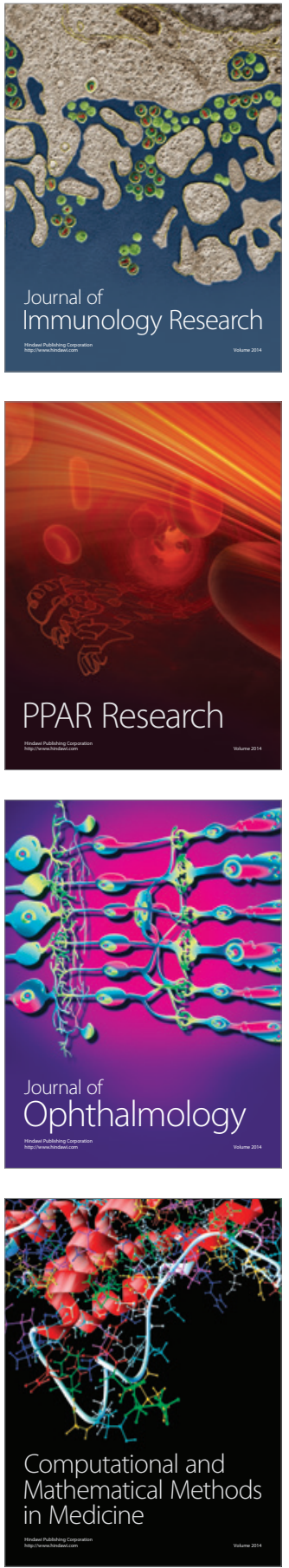

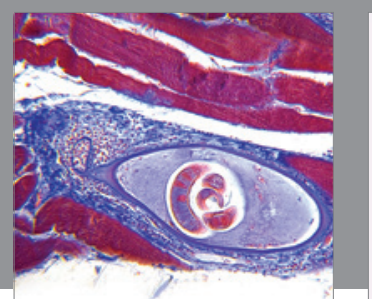

Gastroenterology Research and Practice

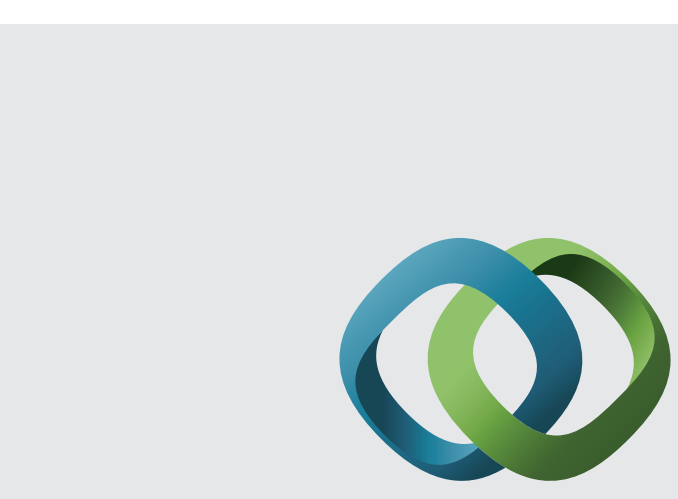

\section{Hindawi}

Submit your manuscripts at

http://www.hindawi.com
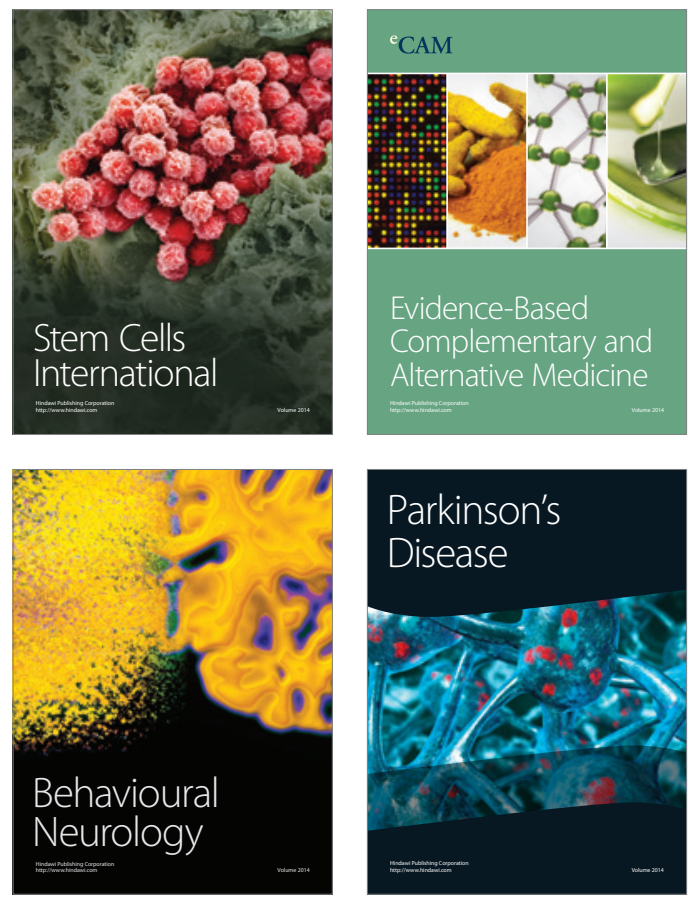
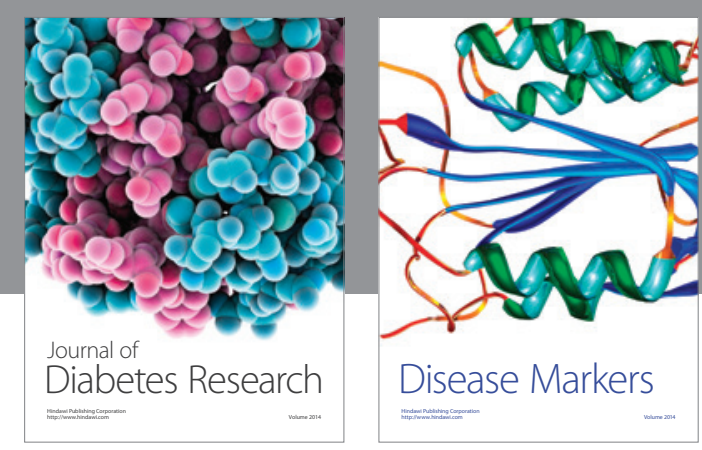

Disease Markers
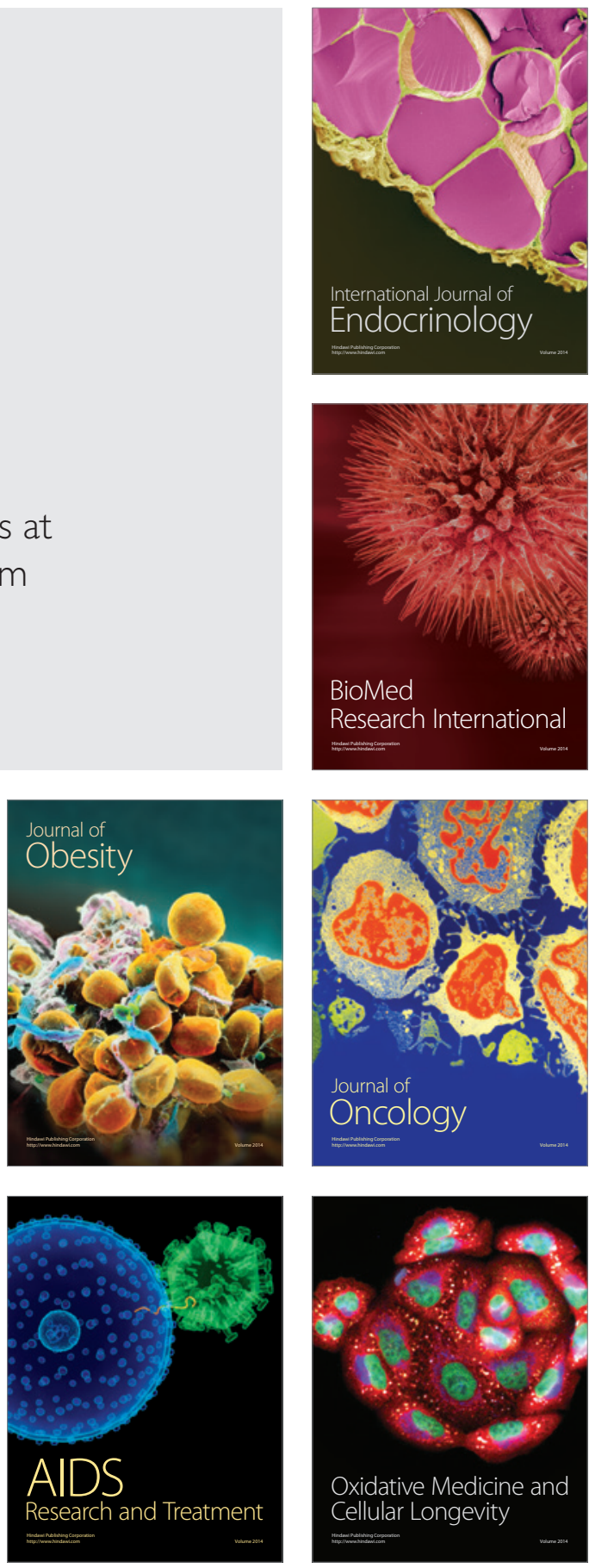